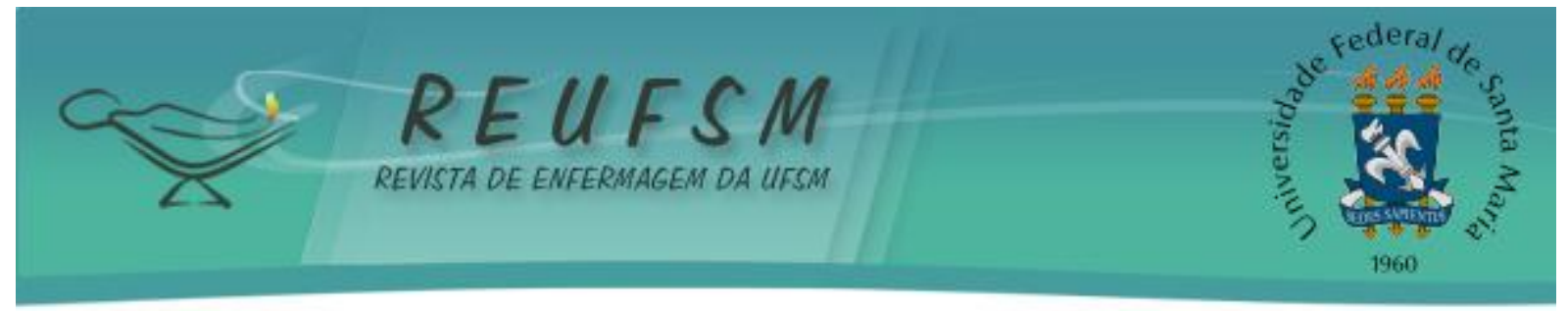

EDITORIAL

\title{
MESTRADO PROFISSIONAL: FORMAÇÃO STRICTO SENSU EM EXPANSÃO NA ÁREA DE ENFERMAGEM
}

\section{PROFESSIONAL MASTERS: STRICTO SESU GRADUATION IN EXPANSION IN THE NURSING FIELD \\ MAESTRIIA PROFESIONAL: FORMACIÓN STRICTO SENSU EN EXPANSIÓN EN EL ÁREA DE ENFERMERÍA}

\author{
Carmen Gracinda Silvan Scochi ${ }^{1}$ \\ Denize Bouttelet Munari²
}

A pós-graduação em Enfermagem encontra-se em expansão, particularmente, na última década, passando de 29 cursos (18 mestrados acadêmicos, 10 doutorados e 01 mestrado profissional), em 2002, para 83 cursos (45 mestrados e 27 doutorados e 11 mestrados profissionais), em 2012, perfazendo atualmente 58 programas distribuídos em todo território nacional. Nas regiões Norte e Centro Oeste ainda há carência de cursos e de formação de massa crítica para garantir o desenvolvimento desse nível de ensino, refletindo uma situação comum a todas as áreas do conhecimento. ${ }^{1}$

A criação do mestrado profissional no Brasil é relativamente recente, tendo como um dos marcos regulatórios a Portaria Normativa $N^{\circ} 7$, de 2 de junho de 2009, revogada pela Portaria $\mathrm{N}^{\circ} 17$, de 28 de dezembro de $2009 .{ }^{2}$ É entendido como modalidade de formação pós-graduada stricto sensu que possibilita:

- capacitação de pessoal para a prática profissional avançada e transformadora de procedimentos e processos aplicados, por meio da incorporação do método científico, habilitando o profissional para atuar em atividades técnico-científicas e de inovação;

- formação de profissionais qualificados pela apropriação e aplicação do conhecimento embasado no rigor metodológico e nos fundamentos científicos;

- incorporação e atualização permanentes dos avanços da ciência e das tecnologias, bem como a capacitação para aplicar os mesmos, tendo como foco a gestão, a produção técnico-científica na pesquisa aplicada e a proposição de inovações e aperfeiçoamentos tecnológicos para solução de problemas específicos.

O mestrado profissional tem como objetivos:

- capacitar profissionais qualificados para o exercício da prática profissional avançada e transformadora de procedimentos, atendendo as demandas sociais, organizacionais ou profissionais e do mercado de trabalho;

- transferir conhecimento para a sociedade em consonância com as demandas específicas e de arranjos produtivos com vistas ao desenvolvimento nacional, regional ou local;

- promover a articulação integrada da formação profissional com entidades demandantes de naturezas diversas visando melhorar a eficácia e a eficiência das organizações públicas e privadas por meio da solução de problemas e geração e aplicação de processos de inovação apropriados.

- contribuir para agregar competividade e aumentar a produtividade em empresas, organizações públicas e privadas. ${ }^{2}$

Nessa perspectiva, a ênfase acadêmica do mestrado profissional difere do acadêmico, pois enquanto esse último inclui disciplinas com conteúdos direcionados a formação do pesquisador e ao desenvolvimento de determinada linha de pesquisa, no mestrado profissional as disciplinas formativas obrigatórias devem abordam conteúdos

\footnotetext{
${ }^{1}$ Professora Titular do Departamento de Enfermagem Materno-Infantil e Saúde Pública da Escola de Enfermagem de Ribeirão Preto da Universidade de São Paulo/USP - Coordenadora Área Enfermagem/CAPES 2011/2014, Ribeirão Preto, SP, Brasil. E-mail: carmenscochi@gmail.com

${ }^{2}$ Professora Titular da Faculdade de Enfermagem da Universidade Federal de Goiás. Coordenadora Adjunta Área Enfermagem/CAPES 2011/2014, Goiânia, GO, Brasil. E-mail: denize@fen.ufg.br
} 


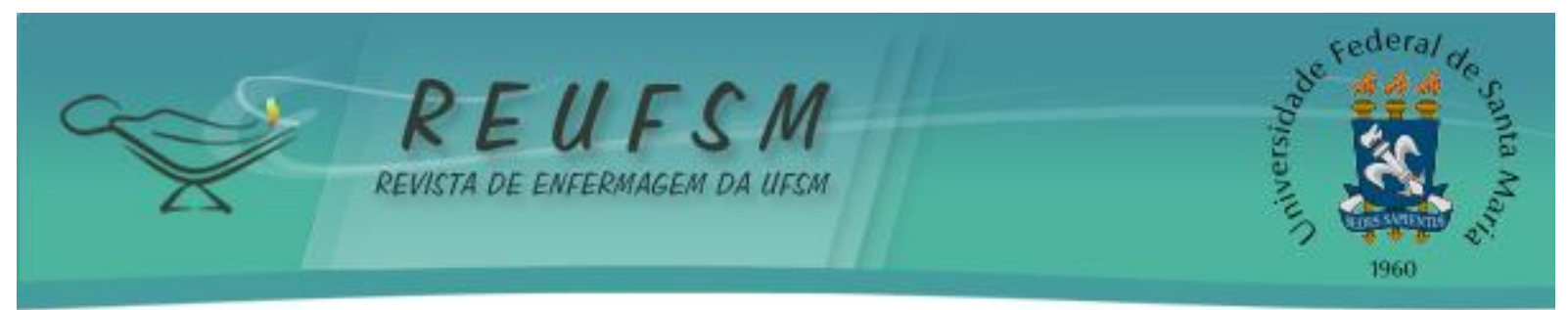

relacionados à atividade profissional e ao desenvolvimento do raciocínio crítico. Assim, diferentemente o foco do primeiro é a geração de conhecimento relacionado à determinada linha de pesquisa, enquanto que o foco do mestrado profissional é a intervenção sobre a prática profissional, o juízo crítico na tomada de decisão e a geração de tecnologia para o mundo do trabalho. ${ }^{3}$

$\mathrm{Na}$ área de Enfermagem o primeiro mestrado profissional foi criado em 2002, na Universidade Federal Fluminense, e somente em 2007 cria-se o segundo junto a UNESP/Botucatu, os quais titularam 52 mestres até a última trienal. A partir de 2010, houve grande expansão dessa modalidade de formação e, atualmente, temos 11 mestrados profissionais assim distribuídos: 08 (NOVAFAPI, UEFS, FECEPS, UFES, 2 na UFF, CUSC e UNSINOS) com nota 3 e 03 (UNESP/Bot, UFSC e UFPR) com nota 4, sendo dois deles localizados na região nordeste, um no centro-oeste, cinco $(45,5 \%)$ no sudeste e três na região sul.

Com a criação da área de Ensino na Coordenação de Aperfeiçoamento de Pessoal de Nível Superior - CAPES, é possível que os mestrados profissionais com foco no ensino sejam lá alocados vinculados a Grande Área Multidisciplinar.

Considera-se que o mestrado profissional na área de Enfermagem constitui modalidade de formação que possibilitará contribuir com a redução do distanciamento entre a ciência e a prática profissional, rumo à prática baseada em evidências e ao desenvolvimento de tecnologias e inovação que atendam as necessidades do mundo do trabalho. Por outro lado, esse processo ainda está em construção na área, apontando-se as questões que se seguem para reflexão:

- Será que os mestrados profissionais da área de Enfermagem têm atingido os objetivos esperados?

- Será que a estrutura curricular tem garantido a formação na área profissional pretendida, o desenvolvimento do raciocínio crítico e a apropriação do método científico para a tomada de decisão?

- Os trabalhos de conclusão têm respondido às necessidades da prática profissional ou gerado tecnologias aplicáveis ao mundo do trabalho? No que diferem das dissertações de mestrado acadêmico?

Essas questões foram motivo de debates no II Fórum de Integração dos Mestrados Profissionais em Enfermagem e II Mostra de Trabalhos/Produtos dos Mestrados Profissionais em Enfermagem realizados em Vitória - ES, em junho de 2012, e organizado pela Universidade Federal do Espírito Santo, cujos resultados apontaram que a formação em nível de Mestrado Profissional na Enfermagem é um processo em construção e que requer atenção especial tanto das Coordenações dos Programas quanto da Coordenação da Área. Considera-se fundamental, tanto na avaliação da trienal 2010-2012 quanto nas orientações e acompanhamentos, que a Área tem feito junto aos programas, que se consiga identificar experiências exitosas dos programas de Mestrado Profissional de forma que esses possam auxiliar na construção de novos indicadores de produtividade tecnológica e de desenvolvimento social.

\section{REFERÊNCIAS}

1. Brasil. Ministério da Educação. Coordenação de Aperfeiçoamento de Pessoal de Nível Superior. Plano Nacional de Pós-graduação - PNPG: 2011- 2020. Brasília (DF): CAPES; 2010.

2. Brasil. Ministério da Educação. Portaria normativa $n^{\circ} 17$, de 28 de dezembro de 2009. Dispõe sobre o mestrado profissional no âmbito da Fundação Coordenação de Aperfeiçoamento de Pessoal de Nível Superior - CAPES. Diário Oficial [da] República Federativa do Brasil, Brasília, DF, 29 dez 2009. Seção 1, p. 20.

3. Barros EC, Valentim MC, Melo MAA. O debate sobre o mestrado profissional na CAPES: trajetória e definições. Revista Brasileira de Pós-Graduação. 2005;2(4):124-38. 